\title{
Genetic variability and genetic diversity of 13 upland rice genotypes for agronomic traits and nutritional qualities.
}

\author{
Akinola TF*, Odiyi AC, Fayeun LS, Ohunakin AO \\ Department of Crop Soil and Pest Management, Federal University of Technology, Akure, Ondo State, Nigeria
}

\begin{abstract}
Upland rice is important for sustainable crop production to meet future food demands. Increase in area planted with low land rice genotypes is constraints because of water shortage due to climate change. Thirteen upland rice genotypes were evaluated in a randomized complete block design with three replications in two years to study the genetic variation and diversity of some agronomic traits and nutritional qualities of the selected upland rice genotypes. Data were subjected to analysis of variance, principal component analysis and cluster analysis. Significant variations were expressed by genotypes for all traits studied. Interaction between genotypes and year exhibited significant differences for all the traits with exception of Panicle Weight (PW) and Tiller Number (TN) where no significant difference was expressed. The highest phenotypic and genotypic coefficient of variation was recorded for grain yield across years. All traits under study exhibited high heritability with exception of Tiller Number (TN) in both years and in year 2 of number days to $50 \%$ flowering number of leaves at 2 weeks after planting and 8 weeks after planting respectively. Cluster analysis based on 15 traits grouped the 13 rice genotypes into five clusters. Cluster III was the largest and consisted of 4 genotypes mostly belonging to NERICA family. The first four principal components of the $\mathbf{1 5}$ principal components accounted for about $96.67 \%$ of the total variation and revealed a wide variation among the genotypes. The best traits, which showed high heritability and high genetic advance, could be used as a selection criterion for hybridization programmers in future breeding.
\end{abstract}

Keywords: Upland rice, Cluster analysis, NERICA, Principal component analysis, Genotypes.

\section{Introduction}

Rice (Oryza sativa L.) is the second most important cereal crop after wheat [1]. Rice is a staple food crop for more than $50 \%$ of the world population. Rice grain contains $75 \%$ to $80 \%$ starch, $12 \%$ water and $7 \%$ protein [2,3]. It is a staple food in many parts of the world including many developing countries. In Nigeria, rice is the most consumed food crop and the sixth most cultivated food crop after millet, sorghum, cowpea, maize and yam [4]. Nigeria has between 4.6-4.9 million hectares of land suitable for rice production out of which only 1.7 million hectares is being cultivated. Although production, harvesting and postharvest operations affect overall quality of milled rice, variety remains the most important determinant of market and end-use qualities [5]. Research results over the years indicated that indiscriminate consumption of rice with little or no attention to its nutritional quality poses threat to the health of consumers. Maintaining rice grain quality to meet the diverse interest groups in the rice sub-sector currently represents a major challenge of rice development in many rice producing areas of the world.

Upland rice adoption is at the forefront of acceptability among peasant farmers due to its high-yielding capacity as well as high nutritional qualities of some genotypes, and its ability to produce well in water shortage regions. Over years, increases in world rice productivity that have resulted from research breakthroughs and transfer of modern technology are majorly on irrigated highyielding varieties. Little or no research findings are available on upland rice, and most of the available research results are yet to be published; therefore, the breakthrough have little or no effects on upland rice production. Upland rice comprises $11 \%$ of the total global rice production and is cultivated on about 14 million hectares [6]. It is also important in cropping systems, since the cost of production is cheap [7]. In Brazil, the mean yield of upland rice is about $2 \mathrm{t} / \mathrm{ha}$, compared to about $5 \mathrm{t} / \mathrm{ha}$ for lowland or irrigated rice [8]. In Nigeria, although the production of rice has increased due to a marked expansion in area cultivated, the productivity per unit area remained at about $1.5 \mathrm{t} / \mathrm{ha}$ [9]. To increase yield potential of upland rice, it is necessary to identify improved yield cultivars coupled with high nutritional quality and other desirable agronomic traits, especially in African countries [10]. Genetic variability is the basis of plant breeding which provides an array of genotypes that can be selected to develop new varieties or breeding materials [11]. Variability in respect to genetic divergence for traits of interests is the major component of breeding programmes for broadening the gene pool of crop and requires reliable estimates of heritability to plan an efficient breeding programme [12]. Adequate understanding of heritability assists plant breeders in predicting the nature of 
the successful generation, to make an appropriate selection as well as assessing the magnitude of genetic improvement through selection. This study was therefore carried out to identify and select potential cultivars and evaluating traits of importance for genetic improvement by exploiting the genetic variation and diversity of some agronomic attributes, yield and nutritional qualities of 13 upland rice genotypes.

\section{Materials and Methods}

The research was conducted at the Teaching and Research Farm of the Federal University of Technology, Akure (FUTA), in 2016 and 2017 planting season. T\&RF FUTA is located between $7^{\circ} 16^{\prime} \mathrm{N}$ and $5^{\circ} 12^{\prime} \mathrm{E}$ at an altitude of $332 \mathrm{~m}$ above sea level. The experiment was laid out in a Randomized Complete Block Design (RCBD) with three (3) replications. Each genotype was planted on a $2 \mathrm{~m}$ triple row plots. Planting was done in 2016 and 2017 respectively. Cultural practices were adopted as recommended. Data were taken on the following traits; Plant height $(\mathrm{cm})$, Number of tillers, No of panicle, Panicle length, Panicle weight, Days to 50\% flowering, Grain yield, 1000 seed weight, Pasting characteristics (Amylopectin, Amylose content, Pasting solubility, Pasting viscosity and Pasting clarity) were determined using a Rapid Visco Analyzer (RVA). The name and the source of the genotypes are shown in Table 1.

\section{Statistical analysis}

Combined Analysis Of Variance (ANOVA) was done using SAS software version 9.2. Principal Component Analysis (PCA) and cluster analysis were done using SAS software version 9.2. The genetic parameters, including the genotypic and phenotypic variance, genotypic and phenotypic coefficient of variance, heritability (broad sense), and the expected Genetic Advance (GA), were calculated using the formula given by Burton and deVane, Johnson et al. [13,14].

\section{Results}

Genetic variability of the characters under study in 13 upland rice genotypes

The result of the mean square estimates of all the characters studied in the combined ANOVA in two years is presented in Table 2 . Highly significant differences $(p<0.001)$ for genotypes were observed for the traits under study. Years were also significantly different from one another for the characters under

Table 1. List of genetic materials and their sources.

\begin{tabular}{|c|c|c|}
\hline S/N & Variety & Source \\
\hline 1 & NERICA 1 & Africa Rice \\
\hline 2 & NERICA 2 & Africa Rice \\
\hline 3 & NERICA 3 & Africa Rice \\
\hline 4 & NERICA 4 & Africa Rice \\
\hline 5 & NERICA 5 & Africa Rice \\
\hline 6 & NERICA 7 & Africa Rice \\
\hline 7 & NERICA 8 & Africa Rice \\
\hline 8 & FUNABOR 1 & Africa Rice \\
\hline 9 & FUNABOR 2 & Africa Rice \\
\hline 10 & WAB 56 - 104 & Africa Rice \\
\hline 11 & OS4 & Africa Rice \\
\hline 12 & OS6 & Africa Rice \\
\hline 13 & IRAT 109 & Africa Rice \\
\hline
\end{tabular}

study with exception of number of leaves and number of days to $50 \%$ flowering. Interactions of genotypes with years $\left(\mathrm{G}^{*} \mathrm{Y}\right)$ were highly significant for all the traits under study except Panicle Weight (PW) and Tiller Number (TN).

The phenotypic variance $\left(\sigma^{2} \mathrm{p}\right)$ of all traits was higher than the genotypic variance $\left(\sigma^{2} \mathrm{~g}\right)$ across years (Table 3$)$; similarly, Phenotypic Coefficient of Variation (PCV) was also higher than Genotypic Coefficient of Variation (GCV) across year (Table $3)$. The highest PCV was recorded for grain yield in year 1 and year 2 (53.17 and 52.33), while the lowest PCV was revealed by amylopectin in year $2(0.48)$. Highest GCV was expressed by grain yield (51.93 and 51.54) across year. Heritability estimates in broad sense were found to be very high (i.e. $>70$ ) for almost all the fifteen traits measured except innumber of leaves, tiller numbers that had $0.00 \%$ heritability, number of days to $50 \%$ flowering in year two $(0.00 \%)$, year two of 1000 seed weight $(0.00 \%)$, and paste clarity that revealed moderate heritability in year $2(52.81 \%)$. Genetic advance as percent of mean ranged from $(0.00 \%)$ in days to $50 \%$ flowering and 1000 seed weight to high $(43.87 \%$ and $33.70 \%)$ for the two years in panicle weight which was accompanied with very low genetic advance $(0.37$ and 0.28).

\section{Cluster analysis}

The Euclidean distance was calculated using standardized mean of the data, and a Ward's minimum variance cluster analysis was constructed. Five major groups were observed among 13 upland rice genotypes based on Ward's minimum variance cluster analysis at a 0.6 dissimilarity coefficient value (Figure 1). Cluster III contained the highest number of genotypes including FUNABOR 1, NERICA 1, NERICA 3 and NERICA 7. Cluster I and cluster $\mathrm{V}$ consists of three genotypes each, cluster II had two genotypes (NERICA 4 and WAB 56-104) and cluster I had only one genotype (IRAT 109).

\section{Principal component analysis}

The PCA was computed to differentiate the genotypes into distinct groups based on similarity of the traits under study. The result of the analysis showed that the first four principal components accounted for about $96.67 \%$ of the total variation and exhibited a very high correlation among them. The first Principal Components axis (PC 1) accounted for $71.48 \%$ of the total variation and was positively loaded with plant height (0.63). PC 2 was positively loaded with number of days to $50 \%$ flowering (0.62), and negatively loaded with plant height $(-0.75)$. PC 5 was positively loaded with 1000 seed weight $(0.85)$, panicle length $(0.22)$, amylase content $(0.21)$, and pasting volatility (0.29). PC 4 was positively loaded with panicle length $(0.70)$, pasting clarity $(0.40)$ and negatively loaded with tiller number (-0.43) and 1000 seed weight (-0.32).

\section{Discussion}

Genetic improvements of crop are basically determined by the nature and magnitude of genetic variability available and the extent of interrelationships of heritable and non-heritable variation among traits of study. This would ensure organized and systematic hybridization programme for establishing genetic variability to be exploited for genetic improvement of the trait under study. The significant difference recorded among 


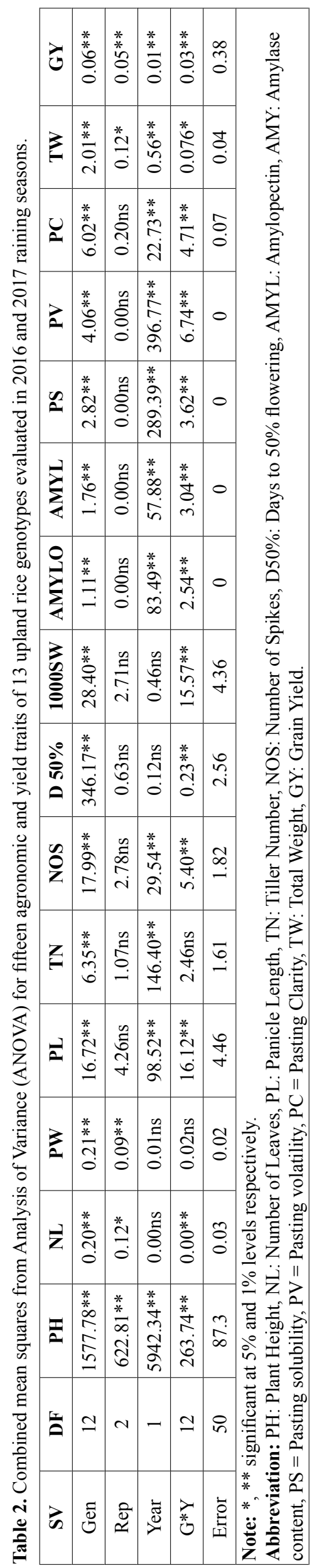

the genotypes is an indication of wide genetic variability among the genotypes evaluated for the different characters studied. This provides good opportunity for selection among the genotypes for both agronomic and nutritional quality traits evaluated indicating that the genotypes can be utilized for further studies. Breeders can effectively employ the genes from this germplasm or recycle the germplasm to enhance nutritional quality and yield in regionally adapted genotypes. All the traits under study showed highly significant differences for year's mean square with exception of number of leaves, days to $50 \%$ flowering and panicle weight which indicates the significant effects of years on the genotypes. The significant interaction between the genotypes and the year recorded for amylopectin, amylose content, pasting solubility, pasting viscosity and pasting clarity is an indication that the genotypes had consistent level of these traits in their grains across years. In agreement with these results, studies on maize reported the presence of minute but significant genotype $\mathrm{x}$ environment interaction for concentration of grain minerals such as beans, rice and wheat $[15,16]$. High PCV over GCV estimates recorded for traits studied is an indication that the environment influences the expression of the traits more than the genotypes. This conformed to the study of Osman et al. where he reported that influence of environment on any trait shows the extent of differences between the PCV and GCV [10].

Therefore, selection based on these characters would be effective for future crossing programmes. However, the close proximity in the values obtained for phenotypic and genotypic coefficient of variation for pasting solubility, pasting viscosity, pasting clarity, amylose and amylopectin content, with high genetic variation and heritability, indicates the presence of genetic variation in addition to noticeable impact by the environment, thereby allowing for its utilization in improving these traits. High heritability recorded for most of the traits showed the presence of additive gene action. This implies that selection based on these traits would be more effective and efficient than the use of traits with low heritability for segregating generations in future breeding programmes, which revealed an exploitable amount of variation. These results conformed to the earlier report of Jahn et al. [17]. High heritability coupled with the high genetic advance revealed in some of the agronomic and nutritional traits is an indication that the concerned traits were mainly under genetic influence and that they can be scored by their phenotypic performance. This result aligned with the result of Vange [9] and Laxuman et al. [18] where the duo revealed high heritability in broad sense with high genetic advance for days to $50 \%$ flowering, panicle weight, panicle length, and 1000 grain weight, tillers number per plant. The clustering of the 13 upland rice genotypes into five groups according to the dendogram chart of cluster analysis in this study aligned with the result of Worede et al. [19] in which they calculated similar clustering pattern for hierarchical cluster analysis for 24 rice genotypes where they identified most similar genotypes based on the dissimilarity coefficient, suggesting that hybridization within these genotypes will not be effective, because of the similar genetic architecture they are made up of. However, crossing between genotypes of diverse genetic background will yield better hybrid because of the divergence in their genes. The Euclidian distance revealed that the clusters were mostly formed based on the origin or geographical area of the 
Citation: Akinola TF, Odiyi AC, Fayeun LS, et al. Genetic variability and genetic diversity of 13 upland rice genotypes for agronomic traits and nutritional qualities. J Agric Sci Bot 2019;3(1):6-11.

Table 3. Phenotypic and Genotypic Variance, Heritability and Genetic Advance and Genetic advance gain of 13 upland genotypes evaluated over two cropping years in Akure, Nigeria.

\begin{tabular}{|c|c|c|c|c|c|c|c|c|c|}
\hline Trait & Year & Mean & $\sigma 2 p$ & $\sigma 2 \mathrm{~g}$ & PCV & GCV & HB\% & GA & GAM \\
\hline \multirow{2}{*}{ PH } & 1 & 131.43 & 169.91 & 160.07 & 9.92 & 9.63 & 94.21 & 25.3 & 19.25 \\
\hline & 2 & 148.5 & 542.3 & 404.6 & 15.68 & 13.55 & 74.61 & 35.79 & 24.1 \\
\hline \multirow{2}{*}{ NL } & 1 & 5.54 & 0.06 & 0.02 & 4.54 & 2.76 & 36.84 & 0.19 & 3.45 \\
\hline & 2 & 5.55 & 0.06 & 0.02 & 4.29 & 2.33 & 29.41 & 0.14 & 2.6 \\
\hline \multirow{2}{*}{ PW } & 1 & 0.84 & 0.05 & 0.04 & 26.62 & 23.81 & 80 & 0.37 & 43.87 \\
\hline & 2 & 0.82 & 0.05 & 0.03 & 27.27 & 21.12 & 60 & 0.28 & 33.7 \\
\hline \multirow{2}{*}{ PL } & 1 & 27.05 & 4.57 & 3.4 & 7.9 & 6.81 & 74.38 & 3.27 & 12.1 \\
\hline & 2 & 29.3 & 10.66 & 5.4 & 11.14 & 7.93 & 50.67 & 3.41 & 11.63 \\
\hline \multirow{2}{*}{$\mathrm{TN}$} & 1 & 9.36 & 1.25 & 0 & 11.94 & 0 & 0 & 0 & 0 \\
\hline & 2 & 12.1 & 2.09 & 0 & 11.95 & 0 & 0 & 0 & 0 \\
\hline \multirow{2}{*}{ NOS } & 1 & 12.13 & 2.81 & 1.91 & 13.83 & 11.4 & 68.01 & 2.35 & 19.37 \\
\hline & 2 & 13.36 & 7.23 & 4.76 & 20.13 & 16.33 & 65.84 & 3.65 & 27.3 \\
\hline \multirow{2}{*}{ D $50 \%$} & 1 & 71.81 & 58.28 & 56.42 & 10.63 & 10.46 & 96.81 & 15.22 & 21.2 \\
\hline & 2 & 71.26 & 1.86 & 0 & 1.91 & 0 & 0 & 0 & 0 \\
\hline \multirow{2}{*}{$1000 \mathrm{SW}$} & 1 & 31.56 & 11.35 & 10.12 & 10.67 & 10.08 & 89.16 & 6.19 & 19.6 \\
\hline & 2 & 31.41 & 7.78 & 0 & 8.88 & 0 & 0 & 0 & 0 \\
\hline \multirow{2}{*}{ AMYL } & 1 & 81.02 & 1.08 & 1.08 & 1.28 & 1.28 & 100 & 2.14 & 2.64 \\
\hline & 2 & 78.95 & 0.14 & 0.14 & 0.48 & 0.48 & 100 & 0.78 & 0.99 \\
\hline \multirow{2}{*}{ AMY } & 1 & 21.92 & 1.29 & 1.29 & 5.17 & 5.17 & 100 & 2.34 & 10.66 \\
\hline & 2 & 20.2 & 0.31 & 0.31 & 2.77 & 2.77 & 100 & 1.15 & 5.71 \\
\hline \multirow{2}{*}{ PS } & 1 & 77.14 & 0.46 & 0.46 & 0.88 & 0.88 & 100 & 1.39 & 1.8 \\
\hline & 2 & 73.29 & 1.69 & 1.69 & 1.78 & 1.78 & 100 & 2.68 & 3.66 \\
\hline \multirow{2}{*}{ PV } & 1 & 33.75 & 3.31 & 3.31 & 5.39 & 5.39 & 100 & 3.75 & 11.1 \\
\hline & 2 & 29.24 & 0.29 & 0.29 & 1.84 & 1.84 & 100 & 1.11 & 3.79 \\
\hline \multirow{2}{*}{$\mathrm{PC}$} & 1 & 65.33 & 3.37 & 3.37 & 2.81 & 2.81 & 100 & 3.78 & 5.79 \\
\hline & 2 & 64.25 & 0.3 & 0.16 & 0.85 & 0.62 & 52.81 & 0.59 & 0.92 \\
\hline \multirow{2}{*}{ TW } & 1 & 4.23 & 0.48 & 0.45 & 16.38 & 15.86 & 93.75 & 1.34 & 31.63 \\
\hline & 2 & 4.06 & 0.26 & 0.22 & 12.56 & 11.55 & 84.62 & 0.89 & 21.89 \\
\hline \multirow{2}{*}{ GY } & 1 & 3.98 & 0.62 & 1.19 & 53.17 & 51.93 & 98.34 & 1.17 & 32.13 \\
\hline & 2 & 4.01 & 3.42 & 5.63 & 52.33 & 51.54 & 97.82 & 2.97 & 38 \\
\hline
\end{tabular}

Abbreviation: PH: Plant Height, NL: Number of Leaves, PL: Panicle Length, TN: Tiller Number, NOS: Number of Spikes, D50\%: Days to 50\% flowering, AMYL: Amylopectin, AMY: Amylase content, PS: Pasting Solubility, PV: Pasting Volatility, PC: Pasting Clarity, TW: Total Weight, GY: Grain Yield.

$\sigma 2 \mathrm{p}=$ Phenotypic variance, $\sigma 2 \mathrm{~g}=$ Genotypic variance, $\mathrm{PCV}=$ Phenotypic coefficient of variation, $\mathrm{GCV}=$ Genotypic Coefficient of Variation, $\mathrm{GA}=$ Genetic Advance, $\mathrm{HB}=$ Broad sense Heritability, GAM=Genetic Advance as percent of Mean.

genotypes. The genotypes from the same geographical origin mostly grouped together; however, the less frequent genotypes from different origins also grouped within the same cluster. This result conformed to the result of Ahmadikhah et al. [20] and Rahman et al. [21] where they grouped 21 rice genotypes into five clusters using 14 physiological traits. Principal component analysis assists in understanding how similar genotypes are group together compared to dissimilar genotypes. PCA results validate the result of cluster analysis; if the results of one analysis support those of another, this confirms that the data are more precise and accurate. The presence of strong differences among 13 upland rice genotypes evaluated in this study was further confirmed by PCA result. The first four principal components accounted for $96.71 \%$ of the total variation, indicating a very strong correlation among the characters under study. The first PC, which solely contributed to $70.07 \%$ of the variation, was the most significant. Based on the PC 1, days to $50 \%$ flowering (0.75) and plant height (0.63) were crucial in separating the genotypes because of their high loadings. This result aligned with the work of [19] where PC 1 and PC 2 explained $61.2 \%$ of the total variation. In the same vein, Lasalita-Zapico et al. [22] reported $82.7 \%$ of the total variability among 32 upland rice genotypes using PC 1 and PC 2. In parental selection, genetic diversity is among the important decisive factors [23]. 


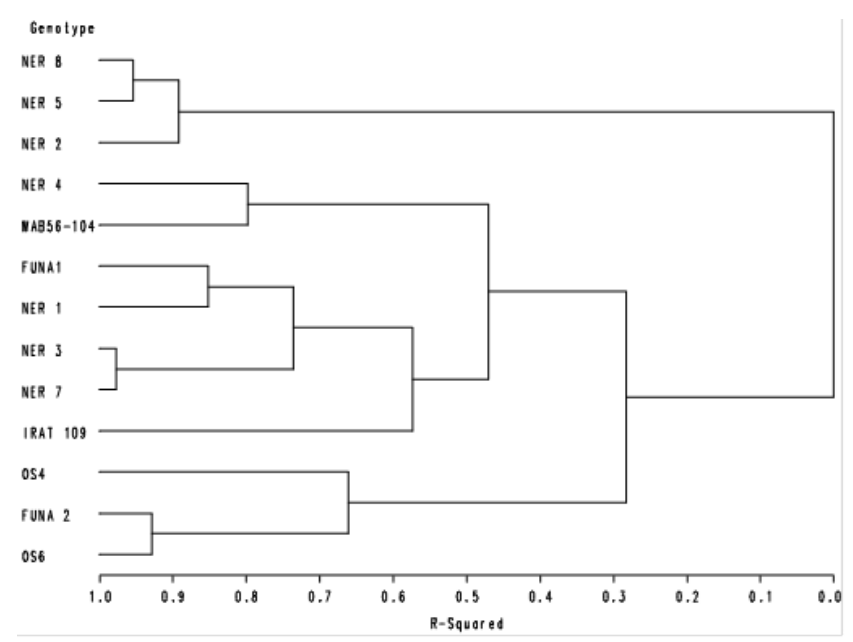

Figure 1. Cluster analysis of 13 upland rice genotypes based on agronomic and nutritional quality associated characters.

Table 4. Eigenvectors and Eigenvalues of the first four principal components of 15 traits.

\begin{tabular}{|c|c|c|c|c|}
\hline Variable & PC 1 & PC 2 & PC 3 & PC 4 \\
\hline PHT & 0.63 & -0.75 & 0.11 & -0.08 \\
\hline NL & 0.01 & 0.01 & -0.02 & -0.01 \\
\hline PW & -0.01 & -0.01 & -0.01 & -0.01 \\
\hline PL & 0.05 & -0.03 & 0.22 & 0.7 \\
\hline TN & -0.04 & 0.03 & -0.07 & -0.43 \\
\hline NOS & 0.12 & -0.04 & 0.01 & 0 \\
\hline $\begin{array}{c}\text { Days to 50\% } \\
\text { flowering }\end{array}$ & 0.76 & 0.62 & -0.16 & -0.01 \\
\hline 1000-SW & 0.02 & 0.18 & 0.85 & -0.32 \\
\hline AMYL & 0.02 & -0.01 & 0.14 & 0.09 \\
\hline AMY & 0.03 & 0.03 & 0.21 & 0.03 \\
\hline PS & 0.04 & 0.03 & 0.1 & -0.14 \\
\hline PV & 0.03 & 0.06 & 0.29 & 0.12 \\
\hline PC & 0.02 & 0.1 & 0.16 & 0.4 \\
\hline TW & -0.04 & -0.02 & -0.06 & 0.08 \\
\hline GY & -0.01 & 0 & -0.01 & 0 \\
\hline Eigenvalue & 84.24 & 24.49 & 3.53 & 2.85 \\
\hline \% variance & 71.481 & 20.782 & 2.9983 & 2.4184 \\
\hline Cumulative (\%) & 71.481 & 92.26 & 95.25 & 97.67 \\
\hline $\begin{array}{c}\text { PC 1=First principle component; PC 2=Second principle component; } \\
\text { PC 3=Third principle component; PC 4=Four principle component. }\end{array}$ \\
\hline
\end{tabular}

\section{Conclusion}

This study revealed the presence of large amount variability and of diversity among the 13 upland rice genotypes. The high heritability expressed by some of the parameters indicates that these traits could be successfully transferred to the next generation, if selection for these characters is performed in the hybridization programme. Traits that expressed high heritability coupled with high genetic advance indicate that these traits could be utilized in selecting upland rice accession for a notable improvement.

\section{Competing Interest}

No competing interest among the authors. All the authors contributed to the research and manuscript preparation equally.

\section{Funding}

The authors used their personal financial facilities for this research.

\section{References}

1. Food and Agricultural Organization. Rice is life. 2004. Available from http://www.fao.org/rice2004/en/f-sheet/factsheet3.pdf

2. Oko A, Ubi B, Efisue A, et al. Comparative analysis of the chemical nutrient composition of selected local and newly introduced rice varieties grown in Ebonyi state of Nigeria. IJAF. 2012;2(2):16-23.

3. Hossain MS, Singh AK, Fasih-uz-Zaman. Cooking and eating characteristics of some newly identified inter sub-specific (indical japonica) rice hybrids. Science Asia. 2009;35:320-25.

4. Fahmi Z, Abu Samah B, Abdullah H. Paddy industry and paddy farmers well-being: A success recipe for agriculture industry in Malaysia. Asian Soc Sci. 2013;9(3):177-81.

5. Danbaba N, Anounye JC, Gana AS, et al. Grain quality characteristics of Ofadarice (Oryza sativa L.): Cooking and eating quality. Int Food Res J. 201;18:629-34.

6. Sohrabi M, Rafii MY, Hanafi MM, et al. Genetic diversity of upland rice germplasm in malaysia based on quantitative traits. Scientific World Journal. 2012;2012:416291.

7. Fageria NK, Carvalho MCS, dos Santos FC. Response of upland rice genotypes to nitrogen fertilization. Commun Soil Sci Plan. 2014;45:2058-66.

8. Fageria NK, Moraes OP, Vasconcelos MJ. Upland rice genotypes evaluation for phosphorus use efficiency. J Plant Nutr Soil Sci. 2013;36(12):1868-80.

9. Vange T. Biometrical studies on genetic diversity of some upland rice (Oryza sativa L.) Accessions. Nature and Sci. 2009;7(1).

10. Osman KA, Mustafa AM, Ali F, et al. Genetic variability for yield and related attributes of upland rice genotypes in semi arid zone (Sudan). Afr J Agric Res. 2012;7(33):4613-19.

11. Pandey P, John P, Anurag DK, et al. Genetic variability, diversity and association of quantitative traits with grain yield in rice (Oryza sativa L.). J Biosci. 2009;17(1):77-82.

12. Akinwale M, Gregorio G, Nwilene F, et al. Heritability and correlation coefficient analysis for yield and its components in rice (Oryza sativa L.). Afr J Plant Sci. 2011;5:207-12.

13. Burton GW, de Vane EH. Estimating heritability in tall fescue (Festuca arundinacea) from replicated clonal material. Agron J. 1953;45(10):478-81.

14. Johnson HW, Robinson HF, Comstock RE. Estimates of genetic and environmental variability in soybean. Agron J. 1955;47(7):314-18.

15. Feila S, Mosera B, Jampatongb S, et al. Mineral composition of the grains of tropical maize varieties as affected by preanthesis drought and rate of nitrogen fertilization. Crop Sci. 2005;45:516-23.

16. Welch RM, Graham RD. Breeding crops for enhanced micronutrient content. Plant Soil. 2002;245(1):205-14.

17. Jahn CE, Mckay JK, Mauleon R. Genetic variation in biomass traits among 20 diverse rice varieties. Plant Physiol. 2001;155(1):15768 . 
Citation: Akinola TF, Odiyi AC, Fayeun LS, et al. Genetic variability and genetic diversity of 13 upland rice genotypes for agronomic traits and nutritional qualities. J Agric Sci Bot 2019;3(1):6-11.

18. Laxuman L, Salimath P, Shashidhar H. Analysis of genetics variability in interspecific backcross inbred lines in rice (Oryza sativa L.). Karnataka J Agric Sci. 2010;23:563-65.

19. Worede F, Sreewongchai T, Phumichai C, et al. Multivariate analysis of genetic diversity among some rice genotypes using morpho-agronomic traits. J Plant Sci. 2014;9(1):14-24.

20. Ahmadikhah A, Nasrollanejad S, Alishah O. Quantitative studies for investigating variation and its effect on heterosis of rice. Int J Plant Prod. 2008;2:297-308.

21. Rahman MM, Rasul MG, Bashar MK, et al. Parent selection for transplanted aman rice breeding by morphological, physiological and molecular diversity analysis. Libyan Agric Res Cent J Int. 2011;2:26-8.

22. Lasalita-Zapico FC, Namocatcat JA, Carĩno-Turner JL, et al. Genetic diversity analysis of traditional upland rice cultivars in Kihan, Malapatan, Sarangani Province, Philippines using morphometric markers. Philippine J Sci. 2010;139(2):177-80.

23. Mazid MS, Rafii MY, Hanafi MM, et al. Genetic variation, heritability, divergence and biomass accumulation of rice genotypes resistant to bacterial blight revealed by quantitative traits and ISSR markers. Physiol Plant. 2013;149(3):432-47.

\section{*Correspondence to:}

Akinola TF

Department of Crop Soil and Pest Management, Federal University of Technology

Akure, Ondo State, Nigeria

E-mail: folorunto@gmail.com 